\title{
bibliographica
}

Golección taurina

\section{"Javier Sánchez Gámiz",}

Biblioteca Nacional de México

The "Javier Sánchez Gámiz"

Bullfighting Collection,

National Library of Mexico

José Francisco Coello Ugalde

Universidad Nacional Autónoma de México

Colegio de Bibliotecología y Estudios de la Información,

Recepción 24.09.17 / Aceptación 27.11.17

DOI: https://doi.org/10.22201/iib.bibliographica.2018.1.9 
Resumen En 2010 ingresó al Fondo Reservado de la Biblioteca Nacional, en calidad de donación, la biblioteca del licenciado Javier Sánchez Gámiz, formada por poco más de 500 títulos. Es la primera ocasión que la Universidad Nacional hace suya una colección con un tema tan específico como polémico: la tauromaquia. El presente texto pretende aportar algunos aspectos relacionados con la forma en que los bibliófilos, especificidad particular que adoptó en vida el propio Sánchez Gámiz, aplican al integrar conjuntos tan peculiares. Hay otros bibliófilos - Carlos Cuesta Baquero, Eleuterio Martínez, Marco Antonio Ramírez o Salvador García Bolio- y organizaciones como los Bibliófilos Taurinos, entre otras, con los que se ha consolidado la bibliografía y hemerografía taurinas en México.

Palabras clave

Abstract

Keywords
Tauromaquia; bibliófilo; catalogación; rarezas bibliográficas.

In 2010 the library of Javier Sánchez Gámiz, over 500 titles, entered the Reserved Fund of the National Library as a donation. This is the first time the National University has adopted a collection on a controversial topic: bullfighting. This paper aims to show some aspects related to the way in which the bibliophiles come to integrate such peculiar collections, particularly that of Sánchez Gámiz. There are other bibliophiles, such as Carlos Cuesta Baquero, Eleuterio Martínez, Marco Antonio Ramírez or Salvador García Bolio, and organizations as the Bibliófilos Taurinos, among others, which contribute to consolidate bullfighting's bibliography, newspapers and magazines in Mexico.

Bullfighting; bibliophile; cataloging; bibliographic rarities. 


\section{Introducción}

La colección está allí, perfectamente acomodada y lista para su consulta. Se agradece a su anterior propietario, y ahora a su nuevo custodio, el significativo acontecimiento que fue estimar conveniente la propuesta de donación ${ }^{1}$ con la que se consumó su ingreso, y no precisamente en cualquier sitio de la Biblioteca Nacional. El Fondo Reservado se convirtió desde ese momento y para siempre en el lugar donde los interesados pueden acceder a la hoy bien conocida colección "Javier Sánchez Gámiz", cuyo tema, leitmotiv o pretexto de integración fue la tauromaquia.

El objetivo de este artículo es valorar la manera en que personajes como Javier Sánchez Gámiz logran concentrar en una colección lo más homogénea posible, temas como la tauromaquia, que tienen su grado de dificultad, sobre todo porque no son obras de fácil acceso y requieren la dedicación de un tiempo razonablemente amplio para conformarla, de acuerdo a las necesidades o aspiraciones que el propio coleccionista aplique a ese propósito.

No es poca cosa armar una biblioteca cuando el tema es o se convierte en un propósito específico. Demasiadas razones son las que llevan a su pretendido coleccionista a darle forma, sentido y razón de ser a un conjunto de libros o publicaciones que además tienen un objetivo fundamental: el de su gozosa posesión y lectura, incluso la afirmación o negación de este o aquel asunto, lo cual siempre despierta polémica sobre este espectáculo. Pero no sólo es eso.

Quien se ostenta con ganas de formar "la" biblioteca debe hacerlo sorteando vientos a favor y en contra, pasando un día y otro también sin que atisbe ni por casualidad el nuevo hallazgo o anhelada sorpresa, que puede serlo si el libro es raro. Hoy muchos libreros saben que el tema se vende por sí solo, por eso lo han encarecido. Aun así, el interesado lo busca, negocia y acaba cediendo ante la tentación de poseer la nueva joya.

Cada libro, cada pieza que va dando forma a la biblioteca es, para el bibliófilo (taurino en este caso), una razón que nutre quién sabe cuántas veces el deleite que significa ver crecer esa colección y saberse propietario de aquello que otros aún no han conseguido.

\footnotetext{
${ }^{1}$ Acceso el 11 de agosto de 2017. http://www.bnm.unam.mx/index.php/biblioteca-nacionalde-mexico/colecciones/fondo-reservado/colecciones-especiales.

Las Colecciones Especiales están formadas por bibliotecas particulares de importantes personajes de la vida política y cultural del país que han sido donadas a la Biblioteca Nacional de México; entre ellas destacan la de Boris Rosen Jelomer, Ángel María Garibay, Rafael Heliodoro Valle y Javier Sánchez Gámiz.
} 
Sin embargo, nos acercamos a un aspecto que construye y fundamenta la biblioteca misma. Se trata de la tipología de los diversos documentos que la integran, la forman y constituyen hasta el punto de obtener la unidad del propósito que persigue su propietario.

De hecho los libros y otros objetos complementarios como publicaciones periódicas, fotografías, carteles y demás fetiches, a lo largo de mucho tiempo han llegado a formar pequeñas colecciones, y hasta sabemos de pronto que esta o aquella pieza perteneció a alguien que en el pasado comulgó con nuestros gustos y elecciones. Así, más de un propietario pone en valor no tanto el significado económico sino el estimativo, lo que da a la biblioteca un plus especial.

Cuando circulan por el mercado o la ruta de la literatura de ocasión, es porque otros propietarios fueron liberando espacios o aplicando la condena de venta, dado el caso de que no sean necesariamente títulos que deben quedar en esas colecciones. Las tribulaciones que suelen pasar los libros pueden ser muchas, y en ese sentido cobran un significado casi de leyenda, de anécdota.

Cuando uno ha dedicado muchos años a este objetivo, formar una biblioteca específica, con tema muy peculiar, se entera de diversos capítulos que son, por su circunstancia, motivo incluso para escribir algunas historias al respecto de la forma en que han llegado hasta nuestros días ciertos libros o, en el peor de los casos, se perdieron para siempre.

El hecho es que esa es, entre una gama importante de síntomas, la forma en que se producen los pasos naturales que luego, en otras circunstancias, permiten en forma azarosa o aleatoria la integración o puesta en marcha de una biblioteca en cuanto tal.

Y quien tiene una biblioteca en casa no pone precisamente en práctica los códigos que la bibliotecología o biblioteconomía establecen como riguroso procedimiento de control. En todo caso, destacan los espacios donde los libros se pueden acomodar según el tamaño, o las secciones como las biografías, sin que nada tenga que ver el hecho de una clasificación o ficha catalográfica que llevan los libros a espacios físicos en forma natural. Su poseedor sabe que en este o aquel sitio encontrará sin dificultad el libro buscado, aun a pesar de que lo que pueda predominar en los estantes sea el caos. En ocasiones cuenta mucho cómo se encuentran ordenados los libros y es posible apreciar en más de una ocasión la similitud que puede haber entre ellos y los tubos de un gran órgano. Van de mayor a menor, y así sucesivamente, en forma acomodada y lucida, por ejemplo.

Con el libro de toros y sus derivados o colaterales, que pueden ser innumerables, estamos frente a un caso en el cual sus potenciales forjadores, en tanto 
coleccionistas, le han dado un sentido, que implica en muchas ocasiones historias rocambolescas.

En ese sentido, el mejor ejemplo es el de Javier Sánchez Gámiz, quien fue abogado de profesión, y se sabe que ejerció dicha profesión con honestidad. También fue bibliófilo taurino por convicción, de ahí que formara una colección que hoy ocupa un lugar de privilegio en el Fondo Reservado de la Biblioteca Nacional de México, lo cual no es poca cosa.

En la página electrónica de dicha Biblioteca, la colección "Javier Sánchez Gámiz" aparece ubicada en el rubro Colecciones Especiales del Fondo Reservado. Sobre nuestro personaje, la reseña indica lo siguiente:

Javier Sánchez Gámiz nació el 2 de diciembre de 1919. Su padre fue el licenciado José Trinidad Sánchez Benítez, quien lo inició en la afición por los toros, si bien después se arrepintió cuando su hijo mostró interés por la fiesta brava, a tal grado que en una ocasión se presentó vestido de luces en una placita aledaña a la Ciudad de México. José Trinidad tuvo que suplicarle que no lo hiciera más o le ocasionaría un gran pesar a él y a su madre. La petición surtió efecto y su retiro de los ruedos fue inmediato, aunque su inclinación nunca cesó y siguió asistiendo como aficionado a las corridas que se daban domingo a domingo en la Ciudad de México, al igual que en otras plazas de la república y algunas de España y Sudamérica.

En El Redondel, periódico mexicano que circulaba sólo los domingos después de las corridas, en su edición del día 30 de abril de 1978, en la sección "Partiendo Plaza", se decía de Sánchez Gámiz:

"En sus años mozos este era armillista ${ }^{2}$ de hueso colorado, no admitía crítica al maestro de Saltillo. Fueron grandes los pleitos que sostuvo en la plaza con aquellos que no compartían con él su armillismo [...] Tenía estatura, buena figura y con los conocimientos taurinos que tenía, hubiera llegado a figura. Leía con deleite el Diccionario de Sánchez de Neira. ${ }^{3}$ Leía al derecho y al revés la Tauromaquia de Guerrita ${ }^{4}$ y todos los libros de toros de aquella época estaban al lado de sus códigos de derecho. "Soy armillista", gritaba en las plazas de toros. En las tardes de triunfo de Lorenzo Garza se entristecía, pero radiaba y era notablemente feliz

\footnotetext{
2 Refiriéndose en particular al torero Fermín Espinosa Saucedo "Armillita" (1911-1978), quien fue uno de los integrantes de la considerada "época de oro del toreo mexicano", la cual tuvo sus mejores momentos durante la tercera y cuarta décadas del siglo XX.

3 José Sánchez de Neira, El toreo. Gran diccionario tauromáquico (Madrid: Imprenta y Librería de Miguel Guijarro, editor, 1879).

${ }^{4}$ Véase en bibliografía la referencia, a nombre de Leopoldo Vázquez [y Rodríguez].
} 
si Armillita ganaba la pelea. Fueron famosas y épicas sus discusiones de toros que sostuvo con el hoy jefe del Departamento Jurídico de la Secretaría de Relaciones, el licenciado Óscar Galeano Pérez. Con Pepe Viesca sostenía atrevidas polémicas. Sabía de toros y criticaba a los toreros con razones, con argumentos. Los toros fueron enaltecidos por este aficionado que era torista antes que torerista y armillista antes que naciera el mundo, como eran sus palabras de pelea en las discusiones en los tendidos. Nunca se enteró Fermín Espinosa que existía un aficionado a los toros que lo defendía más que a sus propios familiares".

En sus últimos años su torero favorito era Manolo Martínez ${ }^{5}$ y finalmente Miguel Espinosa, ${ }^{6}$ el hijo más joven del maestro Fermín.

Debido a esa afición que lo caracterizaba, reunió una colección de libros, revistas y videocintas donde se pueden encontrar títulos como Los toros, de José María de Cossío; Taurología: la ciencia del toro, de Ramón Barga; Las señoritas toreras, de Emilia Boado; Reglamento de corridas de toros: estudio histórico y crítico, de Tomás Ramón Fernández; El Ruedo. Semanario Taurino, y un largo etcétera.?

¿Por qué un libro se vuelve pieza preciada? Así lo ve y estima el bibliófilo, poniendo un valor a piezas que pueden ser inalcanzables o imposibles de poseer. E incluso se hace a la idea de que algún día las obtendrá si para ello sucede un golpe de suerte y tiene oportunidad de conseguir más de uno de esos títulos siempre anhelados, deseados. También se dan los casos donde se declara la obsesión que lleva al bibliófilo por los caminos en los que una biblioteca es el objetivo de sus pretensiones y obsesiones; pasiones, ilusiones o desilusiones al cabo de los muchos años que pueden entregarse para ello.

Al morir el coleccionista, en el mejor de los casos, la unidad de esa biblioteca se conserva intacta y ya sea que algún familiar la herede o termine vendiéndola, respetando ese principio, como pasó con la de Sánchez Gámiz, la cual rebasa los 500 títulos. Lamentablemente esto no sucede en todos los casos, por lo que duele saber cómo se fraccionan las bibliotecas, cómo incluso se comete robo o,

\footnotetext{
${ }^{5}$ Se trata del matador neoleonés Manuel Martínez Ancira (1946-1996), cuyo paso por el toreo representó polémica presencia, debido a la forma en que se encargó de controlar aspectos propios para un "mandón" de los ruedos, como lo fue entre la sexta y octava décadas del siglo XX.

${ }^{6}$ Miguel Espinosa Menéndez, Armillita Hijo (1958-2017), uno de los hijos del célebre Fermín Espinosa Armillita, y quien heredó escuela, aunque desarrolló un estilo propio, no exento de arte.

${ }^{7}$ Consultado el 11 de agosto de 2017. http://www.bnm.unam.mx/index.php/bibliotecanacional-de-mexico/colecciones/fondo-reservado/colecciones-especiales.
} 
peor aún, resultan dañadas o maltratadas algunas de sus piezas al punto de la destrucción, parcial o total. ${ }^{8}$

Por otro lado, el referente de esa biblioteca nos permite tener la certeza de que un tema como el taurino tiene, al menos en nuestro país, garantizada su preservación. Y un aspecto como este evidentemente lo hizo suyo la propia Universidad Nacional Autónoma de México que, en tanto espacio por y para lo universal, tuvo a bien destinarle un preciado rincón a esta colección.

La colección "Javier Sánchez Gámiz" es el ejemplo de alguien que logró formar esa unidad para cubrir las necesidades de un bibliófilo que, con poco más de medio millar de títulos, tendría resuelto el punto con que encarar ya no lo elemental, sino algo más allá para responder a las necesidades del interesado en el tema.

\section{El legado de Javier Sánchez Gámiz}

Esta semblanza, la del personaje y bibliófilo, no puede quedar limitada a unas cuantas referencias. Lo que se aprecia es esa paciente labor que un aficionado a los toros primero, bibliófilo taurino después, puso de por medio para formar su colección. Rigurosamente hablando, debe quedar claro el hecho de que no integró la "gran" colección a que aspira todo interesado en un tema; estuvieron de por medio algunos criterios, que podrían ser de orden personal, la limitación de espacio, el tiempo destinado a obtener cada uno de los títulos. Quizá también haya intervenido el factor económico, que dejo hasta el fin de estas especulaciones, pues a pesar de que pudiera convertirse en impedimento, se tiene por experiencia que el bibliófilo o amante de los libros, echando mano de diversos recursos, obtiene finalmente la preciada pieza que ha sido motivo de inquietudes y hasta de desvelos.

\footnotetext{
${ }^{8}$ Existe el caso de la biblioteca "Salvador García Bolio" del Centro Cultural y de Convenciones Tres Marías, en la ciudad de Morelia, un buen ejemplo de la forma en que su actual propietario, el doctor Marco Antonio Ramírez, ha logrado reunir poco más de 13500 títulos o referencias, formados por ediciones rarísimas, o de aquellas que se han publicado no sólo en países que conservan este legado, sino en otros cuyas lenguas o costumbres no necesariamente son comunes con esta forma de expresión. Pequeños sectores de ciudadanos de dichas naciones que en diversos momentos han podido presenciar el espectáculo de los toros y han sido atraídos al punto de que forman agrupaciones, se reúnen con frecuencia y más de alguno se convierte en autor. Así su propietario, como el propio administrador de la misma (me refiero a Salvador García Bolio), también han logrado con éxito unir, cohesionar lo que queda de otras. Con ello, el nuevo balance es una colección armónica y equilibrada, lo cual constituye el verdadero propósito del bibliófilo en cuanto tal.
} 
Es muy importante destacar -y aquí hago notar que también comparto tan peculiar característica como bibliófilo taurino- que la biblioteca se forma al cabo de muchos años; es posible que haya sido heredada familiarmente y que continúe su enriquecimiento en manos de quien se convierte en poseedor y responsable de la misma. Cuentan, y mucho, los intercambios que puede haber entre quienes poseen libros del mismo tema y que, por alguna razón, tienen materiales repetidos o pretenden deshacerse de ellos, siempre y cuando la razón del trueque surta un efecto compartido.

La gran ventaja que la colección taurina "Javier Sánchez Gámiz" tiene ahora, al encontrarse en el espacio de la Biblioteca Nacional de México, consiste en el hecho de que los usuarios, investigadores e interesados pueden acceder a un conjunto de títulos que permiten resolver, en primera instancia, el encuentro con fuentes específicas, lo cual es de agradecer. Si el propósito es una investigación o la elaboración de una tesis, por ejemplo, esas fuentes proporcionan la información apropiada para que el interesado vaya ubicando otros textos que no necesariamente se encuentran en dicho conjunto. En todo caso, el olfato del investigador tendrá que dar con las obras que han de servir para continuar sus quehaceres.

Las bibliotecas públicas generalmente cuentan con acervos en los que el tema de los toros no es precisamente una de las prioridades, de ahí que al tener al alcance una sólida unidad bibliográfica y hemerográfica como la de Sánchez Gámiz, es posible que el iniciado resuelva sus dudas más importantes. Es cierto que la elección de algún tema con elementos específicos, lleva al investigador a buscar más datos, y existe un sector minoritario, diría incluso microscópico, formado por diversos particulares que poseen este tipo de colecciones; asimismo, en México se encuentra la biblioteca "Salvador García Bolio" o GARBOSA en Morelia, que ofrece un servicio impecable. ${ }^{9}$

\footnotetext{
${ }_{9}^{9}$ El proceso, bastante sencillo, comienza con la ubicación de su página en Internet: http:// www.bibliotoro.com/index.php. Enseguida, el interesado debe comunicarse con sus responsables, a través de la opción "Contacto", para hacerles saber que su propósito es realizar una consulta, la cual debe concretarse in situ. Al formalizarse el acuerdo, hay que acudir a las instalaciones de la biblioteca con el encargado, Moisés Ponce. De ser necesario, pueden realizarse sesiones fotográficas (generalmente sin flash), como sucede en la mayoría de las bibliotecas y archivos de la Ciudad de México. Además, el enorme espacio que ha sido construido para ese propósito, cuenta con un museo que reúne piezas valiosas que datan desde el siglo XVI hasta nuestros días; yambién cuenta con una sala de cine, cafetería, tienda y otras áreas. Si el resultado de esa consulta o investigación se publica, el autor debe dejar dos ejemplares para el acervo y en su obra queda registro del crédito a la institución que le permitió acceder a los fondos.
} 
Un ejemplo similar podemos encontrarlo en Madrid, España, con la Biblioteca "Carriquiri", que cuenta con un acervo semejante al ubicado en nuestro país y que también ofrece los mismos servicios; ${ }^{10}$ ambas instituciones se apoyan mutuamente, al grado de compartir materiales que, por tal o cual causa, no están en la colección de una o de otra. Provisionalmente obtienen reproducciones fotostáticas de algunos títulos, las cuales quedan encuadernadas, ocupando el sitio físico que les corresponderá hasta el momento en que es posible obtenerlos en original.

De todo lo anterior estuvo consciente Javier Sánchez Gámiz cuando fue integrando su biblioteca. Presumirla es uno de los aspectos que suceden normalmente con amigos o conocidos, pero en el fondo cada uno de nosotros sabe el valor implícito que significa ver crecer esa colección, hasta el punto de que se llega a una edad en que deben tomarse decisiones concretas (herencia, donación, depósito o venta). Lo demás, que no viene por añadidura precisamente, queda en las manos de quienes temporal o permanentemente se convierten en nuevos propietarios. Conozco casos verdaderamente dolorosos en los que esta o aquella biblioteca se perdió debido a diversas razones. No entraré en detalles, por tratarse de asuntos privados.

\section{¿Cómo formó Javier Sánchez Gámiz su biblioteca taurina?}

Entre los diversos títulos que la constituyen, un buen número está relacionado con obras enciclopédicas o colecciones que tuvieron esa intención mientras se publicaron de manera programada (tal es el caso de "La Tauromaquia", serie editada por Espasa-Calpe entre 1988 y 1994, aproximadamente). ${ }^{11}$ Tampoco falta en ese conjunto la célebre enciclopedia Los toros, de José María de Cossío, que en su clásica edición consta de 12 gruesos volúmenes. ${ }^{12}$

Allí están los libros considerados como de teoría y técnica taurinas, manuales, historia, fotografía, literatura (en todos sus géneros), biografías, catálogos bibliográficos y hemerográficos, donde es posible apreciar algunas ediciones facsimilares. Se encuentran obras preciadas, como es el caso de El sentimiento del toreo, que escribiera Enrique Bohórquez y Bohórquez, publicada en 1961, o Ayer y hoy: los verdaderos fenómenos, de Daniel Carrasco Zanini, folleto de

\footnotetext{
${ }^{10}$ Puede consultarse en http://www.grupogenova.net/ganaderia-y-biblioteca-carriquiri.

${ }^{11}$ Ésta es una de las colecciones más amplias editadas por tan reconocida empresa, siendo 50 los títulos presentados, que se acompañaron por otros seis volúmenes en una serie denominada "Libro de Oro".

12 José María de Cossío, Los toros. Tratado técnico e histórico (Madrid: Espasa-Calpe, $1974-$ 1997), 12 vols.
} 


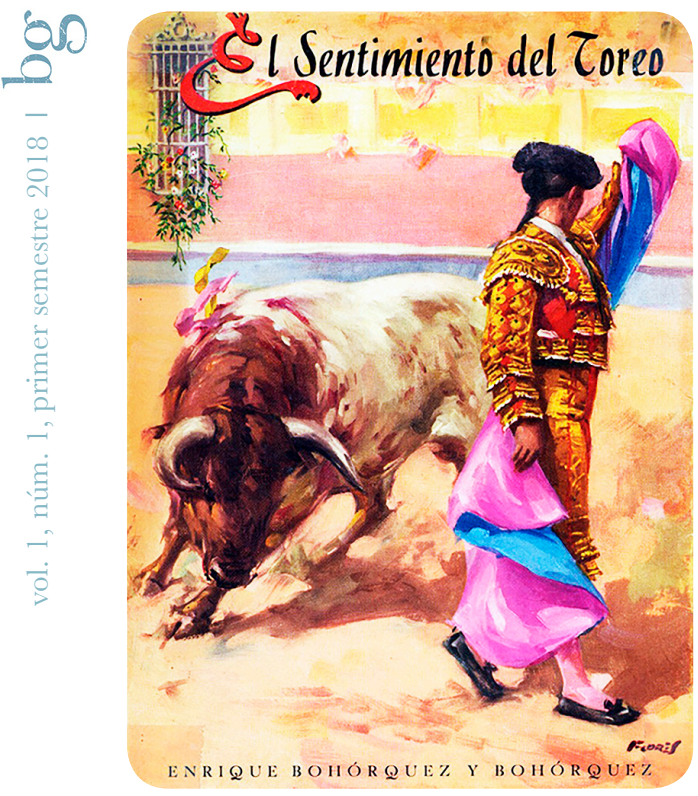

Enrique Bohórquez y Bohórquez, El sentimiento del toreo (México: Imprenta Monterrey, 1961).

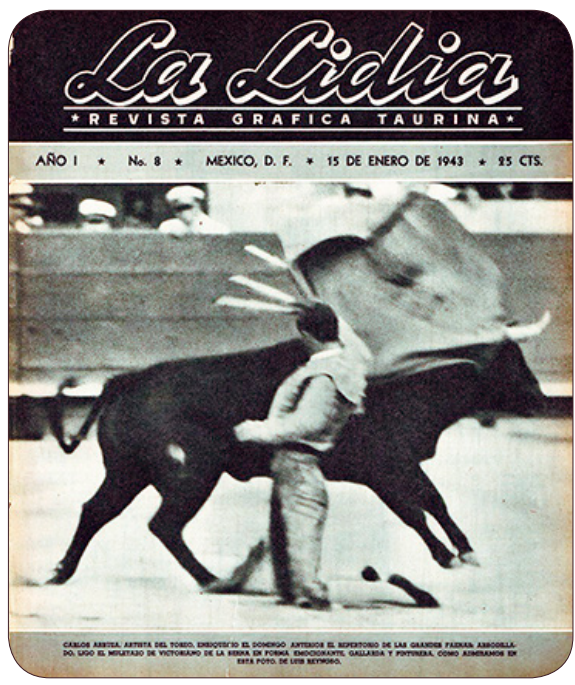

La Lidia. Revista Gráfica Taurina, año 1, núm. 8 (15 de enero de 1943).
38 páginas que fue editado en 1927. Algunos títulos más, escritos en otros idiomas, también se encuentran en el registro, lo mismo que videograbaciones caseras recogidas en diversas épocas, en formatos de 1/2 pulgada, como es el caso también de La pasión por los toros, serie cercana a los 30 casetes (en formato VHS) que impulsó el grupo editorial Planeta D'Agostini entre 1994 y 1995. No faltan las publicaciones hemerográficas como Revista de Revistas, La Temporada, La Lidia, El Universal Taurino, El Taurino y Toros y Deportes, entre otros títulos, todas ellas de gran aprecio por su valioso contenido.

La información complementaria, elaborada bajo los estándares que administra la Biblioteca Nacional (como ficha catalográfica), es posible visualizarla en cada uno de los títulos o autores reunidos en esta colección, lo cual garantiza un acceso apropiado y correcto.

\section{Breve historia de las bibliotecas taurinas en México}

Dicha historia está formada por diversos caminos que arrancan, muy probablemente, con Carlos Cuesta Baquero (1867-1951), uno de los personajes más representativos del espectáculo durante el último tercio del siglo XIX. Con frecuencia el también conocido periodista Roque Solares Tacubac (su anagrama), quien fue colaborador de diversas publicaciones entre 1884 y 1951, solía citar una serie de referencias biblio y hemerográficas que habían sido editadas en España, por lo menos en la segunda mitad del siglo mencionado. ${ }^{13}$ En su propia casa llegó a tener ejemplares de reconocidos au-

13 José Sánchez de Neira, El Toreo. Gran diccionario tauromáquico y José Velázquez y Sánchez, Anales del toreo... 
tores cuyas ideas dieron cimiento a los escritos de quien fuera también eminente médico. Por las referencias que de él se tienen podemos entenderlo como un personaje afecto a los libros y a las antigüedades, y formó una interesante colección de documentos entre carteles, manuscritos y fotografías; buena parte de ese patrimonio desapareció, aunque no su obra, la cual quedó dispersa en las más importantes publicaciones taurinas de nuestro país. Fue autor de una de las obras más buscadas por los bibliófilos, la Historia de la tauromaquia en el Distrito Federal, ${ }^{14}$ de cuyo primer tomo apenas se conocen cuatro ejemplares, en tanto que del segundo sólo hay ubicado uno y estaba incompleto; su complemento fue localizado hace algunos años gracias a que su nieta, María Elena Salas Cuesta, conservó en un costal cientos y cientos de cuartillas que escribió el abuelo, y en ese conjunto se encontraba la otra mitad.

Ya en el siglo XX, podría mencionar a algunos personajes clave que nos permiten suponerlos no solamente como autores o periodistas, también como coleccionistas: Carlos Quiroz, Monosabio, y Rafael Solana, Verduguillo, o Armando de Maria y Campos, a quien dedico los siguientes párrafos.

Cuando uno se acerca a la obra de Armando de Maria y Campos (Ciudad de México, 23 mayo 1897-10 diciembre 1967) descubre un legado caudaloso formado por libros, ${ }^{15}$ revistas $^{16}$ e infinidad de textos en los que predominan las biografías, ${ }^{17}$ reseñas teatrales,${ }^{18}$ conferencias $^{19}$ y el tema de los toros. ${ }^{20}$ Seguramente

${ }^{14}$ Carlos Cuesta Baquero, Historia de la tauromaquia en el Distrito Federal desde 1885 hasta 1905 (México: Tipografía José del Rivero, sucesor, y Andrés Botas, editor, [1905, 1920?]), tomos 1 y 2.

${ }^{15}$ Su obra, publicada en vida, así como toda aquella editada tras su muerte, rebasa los 100 títulos, algunos de los cuales se mencionan notas más adelante.

16 Además de Mefistófeles (1917-1919), colaboró en otras publicaciones: Gaoneras (1924-1925), El Eco Taurino (1925-1940), El Redondel (surgido en 1928), La Lidia (entre 1942 y 1945), The Art of Mexico, El Nacional, Novedades y El Heraldo de México.

${ }_{17}$ Algunos ejemplos: Ponciano, el torero con bigotes; Memorias de Vicente Segura. Niño millonario. Matador de toros. General de la Revolución; Vida dramática y muerte trágica de Luis Freg. Memorias y confesiones; Andanzas y picardías de Eusebio Vela (autor y comediante mexicano del siglo XVIII).

${ }^{18}$ El Eco Taurino. Revista de Información, Opinión y Comentario (1925-1940) fue la de más larga vida entre las publicaciones donde colaboró; Maria y Campos fue su director propietario.

${ }^{19}$ Ejemplo: la "Conferencia radiada durante 'La Semana del Periodista" (27 nov. - 4 dic. 1932), que trató sobre la historia de las publicaciones taurinas mexicanas de finales del siglo XIX e inicios del XX.

20 Títulos sobre tauromaquia: Los toros en México en el siglo XIX, 1810-1863. Reportazgo retrospectivo de exploración y aventura; Gaoneras (ensayos sobre estética taurina); Imagen 
hay más -como el coleccionista- ${ }_{1}^{21}$ que son algunas de esas vertientes que integran a personajes con este perfil.

Por fortuna, otro caso más es el del ingeniero Eleuterio Martínez, personaje a quien podemos considerar el primer bibliófilo taurino en cuanto tal. Los siete volúmenes ${ }^{22}$ que, bajo el título de Libros de toros, publicó entre 1957 y 1962 y reúnen 3500 obras de su colección (dejó un octavo en proceso "hasta el cuarto millar. 3501 a 4000 y una versión mecanuscrita para el tomo nueve, de la 4001 a la 4500") son el mejor ejemplo de una labor en la que puede apreciarse la elaboración de fichas abreviadas, organizadas en forma alfabética. Formó parte de la organización de los Bibliófilos Taurinos Españoles, ocupando la silla número 81 de 200 integrantes, y a él se deben muchos empeños que hicieron suyos otros bibliófilos surgidos generaciones más tarde. En ese sentido, fue referente y modelo a seguir, hasta el punto de que el 21 de julio de 1984 se creó en la Ciudad de México el primer grupo organizado: los Bibliófilos Taurinos de México, que algunos años después se constituyó como asociación civil, que se mantiene vigente y renovada en 2018.

Fueron Julio Téllez y Heriberto Lanfranchi quienes lanzaron la convocatoria a través del programa "Toros y Toreros" que se transmitía por el canal 11 de televisión, al mediar 1984. Por cierto, Téllez llegó a poseer una rica biblioteca y hemeroteca taurinas, que custodió durante más de 50 años.

Entre las diversas publicaciones de este grupo, es común encontrar la lista de sus integrantes o de quienes lo fueron, ya por haber muerto o haberse separado a causa de una u otra circunstancia.

En las propias publicaciones de su reconocida Colección de Lecturas Taurinas incluyen, tanto en la tercera como en la cuarta de forros, los títulos publicados desde 1987 y hasta nuestros días. A continuación el registro de los mismos:

del mexicano en los toros; Breve historia del teatro en Chile... y de su vida taurómaca. Su obra fue tan caudalosa que en 1946 Agustín Millares Carlo y Francisco Gamoneda, a la sazón director y secretario de la Sociedad Mexicana de Bibliografía, respectivamente, informaron a Armando de Maria y Campos sobre su elección unánime como socio fundador.

${ }^{21}$ De Maria y Campos fue un coleccionista peculiar, pues llegó a reunir infinidad de documentos, impresos, fotografías y otras evidencias que con los años pasaron a manos de otros particulares e instituciones como el Centro Nacional de Investigación, Documentación e Información Teatral Rodolfo Usigli (CITRU) o el Centro Nacional de Investigación, Documentación e Información Musical "Carlos Chávez" (Cenidim), y ahora el Centro de Estudios Históricos de México (Carso), que custodian tan valioso legado.

22 Eleuterio Martínez, Libros de toros (México: [s. e.], 1957-1962), 7 vols. 


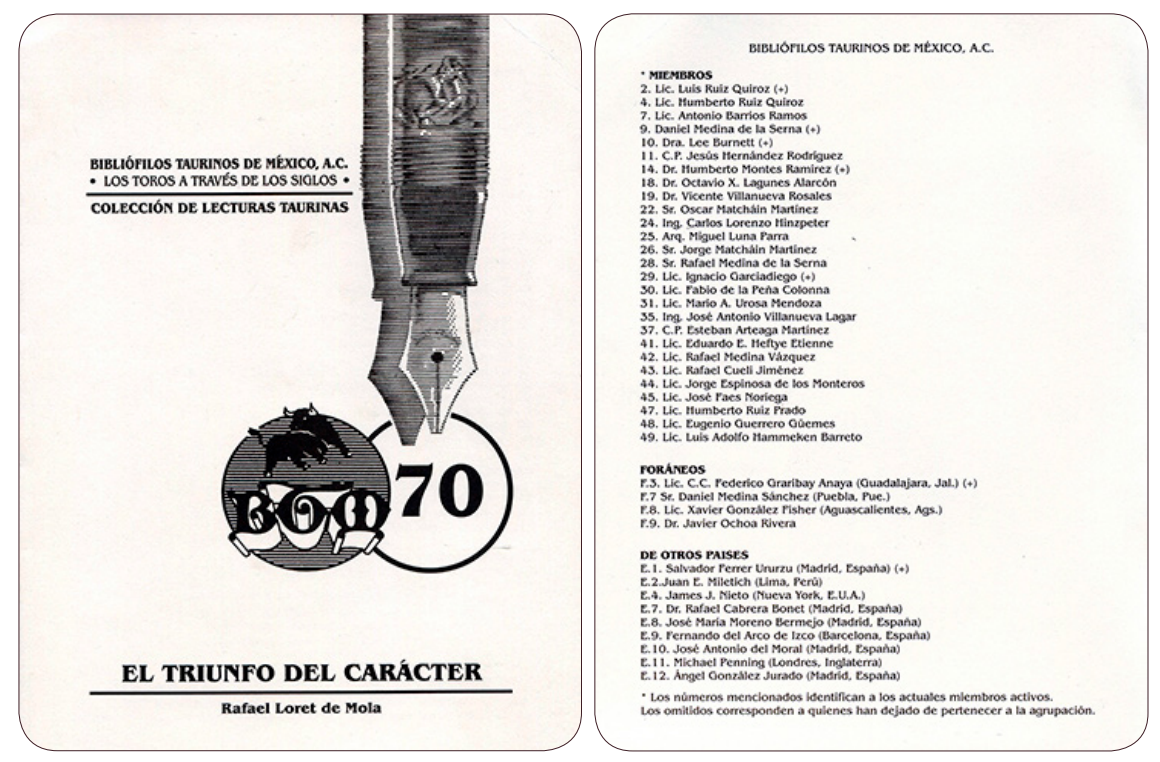

Portada y segunda de forros correspondiente a Rafael Loret de Mola, El triunfo del carácter (México: Bibliófilos Taurinos de México, 2015).
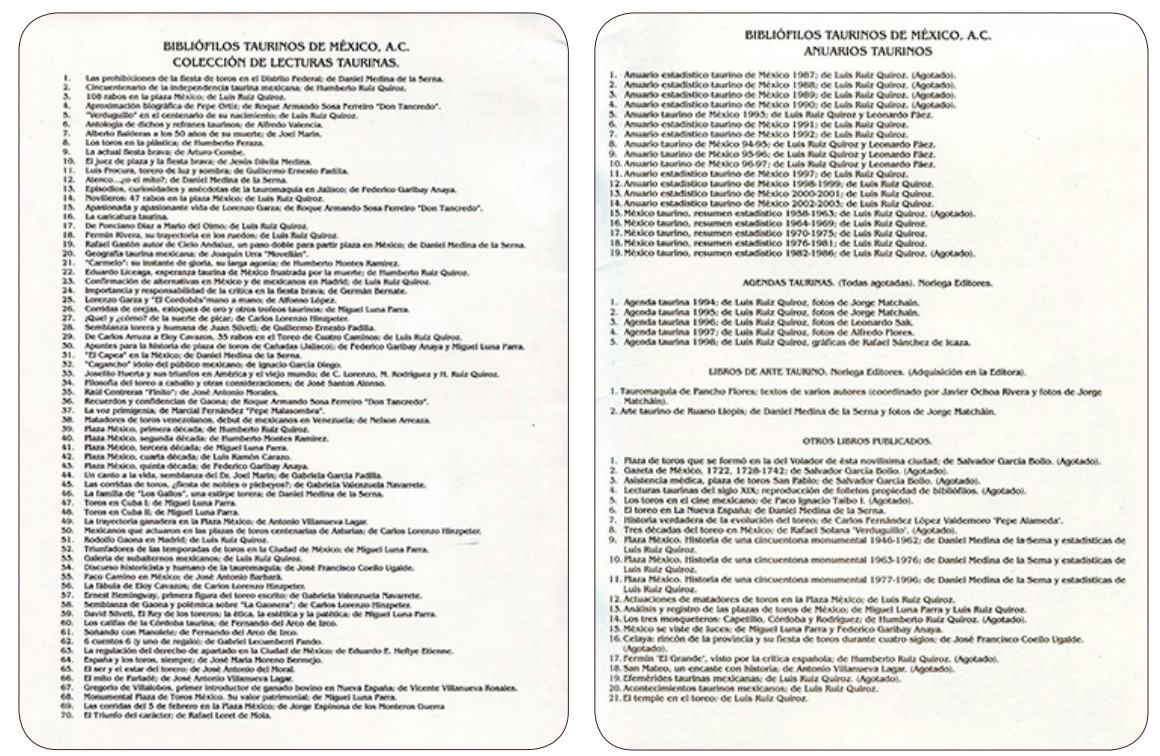

Tercera y cuarta de forros de Rafael Loret de Mola, El triunfo del carácter. 
En Morelia, tiempo después también surgió su primera "sucursal" y en tan estimado espacio provinciano los Bibliófilos Taurinos de Morelia dejaron muestra de interés tan particular, siendo su mejor ejemplo el que hoy se materializa en el Centro Cultural y de Convenciones Tres Marías gracias a la labor de dos personajes clave: su propietario, el doctor Marco Antonio Ramírez, y su encargado, el señor Salvador García Bolio, ambos reconocidos bibliófilos taurinos.

\section{Las experiencias más notables entre los bibliófilos taurinos}

Además de que constituye para cada uno de ellos un proceso en el que están de por medio el gusto, la afición y a veces una desmedida pasión, no sólo la que aplica en su condición de aficionados sino la que viven como bibliófilos, el hecho es que cuando, por ejemplo, uno lee los textos que acompañan los siete volúmenes que formó el ingeniero Eleuterio Martínez, se encuentran verdaderas revelaciones que sus prologuistas dieron al tener ante sí cada uno de los catálogos que publicó de manera especial este peculiar personaje entre 1957 y 1962.

La primera opinión elogiosa, como todas las que aparecieron al principio de cada uno de los siete tomos, fue del entonces joven periodista Jorge Fosado Balderas, quien escribió, entre otras cosas:

No se descuidó un detalle [en su biblioteca]: ordenadas las obras por materias. Historia, Técnica, El Toro, Diestros, Tragedias, Arte, Novela, Poesía, etc., y empastadas en holandesa roja las del siglo XIX y en piel y tela las que corresponden a nuestro siglo se observa un admirable deseo de completar el toque de cuidado y dedicación (vol. I, 1957, 13).

Manuel Horta hizo acto de presencia en el segundo de ellos, y también escribió:

Quien tenga la suerte de penetrar al recinto donde lucen las encuadernaciones más pulcras y las colecciones de revistas dedicadas al bizarro espectáculo, pasará largos paréntesis deleitosos. Ahí está la Filosofía de los Toros, de Abenamar, impreso en Madrid el año de 1842, La Historia de la Tauromaquia del doctor Cuesta, El Arte de Mazzantini de Dos Barbianes, verdadera curiosidad bibliográfica, la segunda edición mexicana de la Tauromaquia de Pepe Hillo y hasta notas en la Gaceta de México, impresas en el siglo XVIII (vol. II, 1958, 15). 
Asimismo, comparece Armando de Maria y Campos, ahora en el tercer volumen y, entre otras cosas, esto fue lo que observó:

Con afición taurina, con paciencia franciscana, con pasión delirante, con sacrificios económicos fui formando una biblioteca especializada, y mi ambición fue constante por lograr clasificarla. ¡Saber lo que tenía y encontrar lo que buscaba o me hacía falta! Nunca pude lograrlo, y ahora con más tristeza que nunca sé lo mucho que tengo y lo difícil que es saber lo que realmente tengo y dónde lo tengo...

No es difícil, a lo largo de una vida, reunir una biblioteca taurina, incluyendo todas las ramas artísticas que con ella se comunican, como la magnífica de don Eleuterio Martínez. Lo que sí es casi obra de santos es clasificarla, cautivarla en un catálogo, y luego darle alas al catálogo en forma de libro para que vuele por todos los rumbos del mundo taurino y se pose en las manos de los que amamos la historia que recoge el fugaz momento que es siempre un lance o un suceso taurino (vol. III, 1958, 11-12).

En el cuarto, con advertencia del propio Eleuterio Martínez, se percibe un interés particular por señalar qué objeto tuvo esa empresa, la de catalogar su propia biblioteca taurina, en estos términos:

Mi propósito no ha sido otro, sino el de dar a conocer a los amantes de esta noble y antigua Fiesta, el acervo de mi Biblioteca, libros y folletos que doy gustosamente a la publicidad en forma de lista simple para que los que estén interesados en estas disciplinas sepan de su existencia en nuestro país y puedan en un momento dado recurrir a ellos como fuente de información, pues como digo, diversas personas han supuesto que estoy formando una bibliografía de la Tauromaquia, cosa enteramente ajena a mi intención.

En el mismo volumen, quien fue invitado a escribir una semblanza sobre aquel trabajo fue el reconocido periodista José Jiménez Latapí, Don Dificultades. Con su sarcasmo característico, y también con buena pluma, dejó varios párrafos que no tienen desperdicio. Veamos.

\section{Eleuterio y Clío}

Mi admirada señora Doña Clío -y le digo señora, porque las Musas no podrán ser nunca resecas solteronas- tiene que estar agradecida profundamente a bibliófilos y bibliómanos, porque ellos son sus manantiales. Al hacer el distingo 
entre bibliófilos y bibliómanos pienso que aquellos son, de acuerdo con sus raíces gramaticales, amantes de los libros, pero no de su contenido en sí, sino de la cosa rara, del incunable preciado; y en cambio los bibliómanos son los amantes apasionados del arte a través de los libros. Yo, con perdón de los graves señores, califico a los bibliófilos como "ratas de biblioteca", primos hermanos de las "ratas de sacristía" a los que los sacerdotes eruditos y talentosos llaman "quita-tiempo"; tales roedores son amorosos cultivadores de lo externo y en cambio los bibliómanos son en verdad amantes de la obra que llevan a cabo, sienten el arte de la bibliomanía; y como quien no es artista en la vida no tiene derecho a vivir, yo admiro fríamente en su tarea, labor, trabajo, a los bibliófilos, pero por los que siento admiración cálida y apasionada es por los bibliómanos en cuya secta tengo para mí, al ingeniero Eleuterio Martínez a quien conozco, jay!, hace muchos años desde una inquieta corrida poblana que vimos juntos y en la que a falta de arte y sabor en el ruedo nos embelesamos con el presente que habían hecho las monjitas al ingeniero, camotes con el más fino y refinado arte, que cubría un sabor delicioso de dulce poblano. Entre palabra y palabra tal parece que andamos haciendo faena de esas modernas, desperdigadas, espasmódicas y errabundas. Decíamos que Clío mucho debe a bibliófilos y bibliómanos y díganme ustedes si hay justicia en la aseveración cuando vemos, y las siguientes generaciones verán, que todos los hechos históricos, que todas las grandes gestas, que cuanta investigación humana emprende, está hecha sobre la base de la bibliografía que da, podríamos decir, en sus contrastes, la mayor cercanía a la verdad que buscan quienes desean hacer la humanidad que tan escasamente anda de ella. Yo peco un poquitín en eso de la bibliomanía y por tal, quizá entiendo el placer de ello. A mí me ha dado por cuanto se refiere en letras de molde a Bolívar, único héroe continental de esta Indo-lberia, y cuando me hago de una obra preciada acerca del hombre de la lucha con y en los Andes, me emociono grandemente y veo que mi señora Doña Clío estaría perdida sin los amantes burgueses y secos que son los bibliófilos y los amantes turbulentos y artistas que son los bibliómanos.

Ya refiriéndonos a la bibliografía taurina, el círculo se estrecha, y resulta más admirable la afición de quien anda en pos y ansia de un libro, folleto o papeles sueltos que se relacionan con la ex - gran fiesta de los toros, que también andan en peligro de que se les anteponga el ex, que como decía un político amigo, es algo así como el síntoma de la decadencia.

Cuando la amada fiesta taurina que nos ha dado tantos dolores de cabeza y sacudimientos de nervios desaparezca (eso de la eternidad de ella ya lo andamos dudando porque no hay quien resista tanta puñalada de tan numerosos zascan- 
diles, pela-brevas, rasca-buches, limpia-botas, quídams, estultos, prevaricadores y miserables), será una de las más interesantes cosas a investigar, ya que la fiesta bravía ha sido y es trasunto fiel del espíritu de una raza y exponente del sentido de belleza y valor de varios pueblos. ¿Cómo podrán saber los que vengan tras nosotros lo que en realidad ha significado la táurica diversión para nuestros antecesores y para nosotros? Solamente a través de la obra de los bibliófilos y los bibliómanos, y entonces Doña Clío tiene que regodearse porque hayan vivido gentes que se preocuparon por enriquecer y ordenar los elementos que habrán de dar luz, resplandor goethiano, en la investigación taurina que habrá de seguirse, ya que las civilizaciones helénica y árabe son inmortales, y la agonizante fiesta (uso la palabra agonía en el sentido meramente unamunesco de la lucha) tiene, a no dudarlo, sus raíces por ahí por las árabes tierras y por las helénicas praderas. Para asentar el helenismo del arte taurino se me ocurre el pensar que los toreros buenos siempre torean con la gracia vertical del Partenón.

Fíjense ustedes bien si tiene mérito la labor del ingeniero Martínez, que con su Biblioteca Taurina, la cuarta en el mundo, según dicen los técnicos, está jugando nada menos que con la inmortalidad.

Como la función del prologuista es la del telonero en los teatros, aunque un poco lentamente les digo a los lectores: El escenario está ahí, a su disposición, y el telonero se va (vol. IV, 1959, 12-13).

Es evidente que el primero en hacer un reclamo amistoso, apenas un párrafo más adelante, fue el propio Eleuterio Martínez, quien advertía en esta

\section{Pequeña discrepancia}

Con el cariño y respeto que me merece mi querido y viejo amigo "Don Difi", extraordinario escritor e incansable defensor de La Fiesta, permítaseme manifestar que difiero en algunas de sus apreciaciones.

Para mí, bibliómano es aquel que tienen pasión desordenada de coleccionar libros, y bibliófilo la persona aficionada a éstos.

También entró a la palestra el reconocido diplomático e historiador Francisco González de Cossío, quien puso su "cuarto a espadas". Entre lo muy importante que dejó escrito, dos cosas llaman la atención: una de ellas tiene que ver con algunos datos biográficos de nuestro personaje, en tanto que el otro asunto lo dedica a destacar la antigüedad y rareza de algunas de las obras que estuvieron en esa biblioteca taurina. 
Originario de Monterrey, cursó sus estudios en el Saltillo, de cuyo colegio de San Juan Nepomuceno salió para la Universidad de Michigan, fundada en 1817, en donde obtuvo el título de Ingeniero Civil. Dedicado de lleno al ejercicio de su profesión, en la que ha tenido muchos y merecidos éxitos, ha servido a nuestro Gobierno con eficiencia y honorabilidad sin mengua, habiendo representado a la República Mexicana en el Congreso Mundial del Petróleo en Tulsa, Oklahoma, el año 1930. Actualmente atiende con iguales méritos la Dirección General de Catastro e Impuesto Predial del Departamento del Distrito Federal, colaborando infatigablemente en la más brillante administración que desde los tiempos de Revillagigedo, el segundo conde, ha regido nuestra seis veces centenaria Ciudad de México.

Entre las preseas de su valiosa colección figuran la edición facsimilar de la obra del Comendador de Montachuelos, impresa en 1551, que se considera el primer libro sobre la materia; el rarísimo Tratado del Juego, de Fr. Francisco de Alcocer, teólogo franciscano que dedica el capítulo 53 a la fiesta de toros, impreso en Salamanca por Andrés de Portonaris en 1558-1559; una edición de las Siete Partidas de don Alfonso el Sabio, de mediados del siglo dieciséis, que no es la primera, por serlo la de Meynardo Ungut y Lanzalao Polomo, de Sevilla, año de 1491; obras de ediciones del siglo pasado, de cortísimas tiradas, 12, 15 y 25 ejemplares, y otras, de que el buen lector tendrá mejor noticia al recorrer las páginas de este volumen que, como los anteriores, nos sugieren, en tiempos idos y en brumas de leyenda, sucesos encantados y hazañas fabulosas.

Esperamos que algún día don Eleuterio Martínez reimprima, para solaz y enseñanza de los taurófilos de América y de España, algunas de esas joyas bibliográficas, y que el brillo de su valor resplandezca para unos y para otros (vol. V, 1960, 9, 11).

Por último, en el tomo VII de ese tenaz ejercicio logrado por Eleuterio Martínez, aparecen un par de textos, los que escribieron Don Indalecio, seudónimo de Ramón Lacadena Brualla, marqués de la Cadena, autor de una decena de libros taurinos, así como los interesantes apuntes de Antonio de Onuba. En ambos casos quedan aclaradas algunas dudas sobre quienes -antes de la presencia del ingeniero Martínez- dedicaron, sobre todo en España, su tiempo y recursos a esta apreciada actividad que bibliófilos y bibliómanos agradecemos infinitamente. Don Indalecio pone el "punto sobre las íes" como sigue:

Gracias a los "don Eleuterios" que van surgiendo por el mundo taurino los bibliófilos y bibliógrafos nos vamos conociendo. La Unión de Bibliófilos Taurinos ha hecho mucho para ello. Y en este caso, personalmente, ha hecho mucho en nuestro 
favor don Eleuterio, el ingeniero, que tiene sus libros, su dinero y se lo gana. Dios se lo pague.

Antaño -no muy antaño- teníamos que contentarnos con el catálogo de Carmena y Millán, muerto en 1903, vendedor de su biblioteca al extranjero, y anticuado por tanto.

Algo se ganó después, aunque muy poco, con la publicación del catálogo compendiado de Simón y Bris, a base de la biblioteca de Ortiz-Cañabate (año de 1915) hasta entrar ya en la vía ancha del catálogo de Díaz Arquer, catálogo lujosísimo que para las citas nos sirve de apoyo a los bibliófilos.

Preludio de los ensayos particulares fue en España el catálogo de don Antonio Urquijo de Federico, tampoco puesto a la venta. Más el modesto ensayo, publicado en folletín de Dígame de la colección de don Ricardo García, K-Hito.

Luego..., a ver quién sigue. El conde de Colombí podría ser ese. Como podría ser Videgain o Auguste Lafront, Paco Tolosa, tan amantes del libro y tan benefactores de los bibliófilos, ellos podrían continuar la lista...

Los catálogos de colecciones taurinas nos ayudan para averiguar, para descubrir dónde se publicó un folletuco sin importancia y en qué libro de título no torero se encierra materia tauromáquica, no desdeñable (vol. VII, 1962, 11, 13).

Hasta aquí Don Indalecio. Respecto a las notas de Antonio de Onuba, representan el complemento perfecto para toda esta radiografía que ha pretendido el presente texto, y que va llegando a su fin.

Como antecedentes en la materia no conocemos más que dos: el "Catálogo de la biblioteca taurina", de don Luis Carmena y Millán, publicado en 1903, y el "Catálogo de la biblioteca taurina", de don Antonio Urquijo de Federico en 1956. La colección de Carmena y Millán se encuentra en Estados Unidos, en una biblioteca de Washington. Pues la adquirió en 1904 la "Spanish Society", tras la muerte de don Luis. Existen otros dos catálogos de publicaciones taurinas: el "Compendio del catálogo manuscrito de la colección taurina de don Miguel Ortiz Cañabate" -año 1915- y "Libros y folletos de toros" (a la vista de la biblioteca taurómaca de don José Luis Ibarra), por Graciano Díaz Arquer, colección radicada actualmente en la Diputación de Pamplona, pero estas dos obras no son propiamente catálogos bibliográficos.

Entre los primeros bibliófilos del mundo en esta especialidad, se encuentra, por tanto don Eleuterio Martínez, el tercer coleccionista del tema que publica la relación de obras que ha logrado reunir sobre la fiesta brava. Tres mil títulos es una cifra muy considerable, solamente rebasada -ya que Carmena e Ibarra no 
llegaron a ella- por Antonio Urquijo. Éste, y el marqués de la Cadena y el conde de Colombí -bibliotecarios inéditos- forman, con el ingeniero mexicano señor Martínez, los mejores coleccionistas en materia bibliográfica taurina (vol. VII, 1962, 16, 17).

Este ejercicio también lo concretaron en su momento Salvador García Bolio, ${ }^{23}$ Antonio Barrios ${ }^{24}$ y Luis Ruiz Quiroz. ${ }^{25}$ Sin embargo, el mayor propósito, que además ya se ha materializado, es el de la biblioteca del Centro Cultural y de Convenciones Tres Marías, logrado por el propio García Bolio al generar el paciente trabajo de un catálogo con fichas abreviadas de las actualmente más de 13500 piezas, entre libros, folletos, fotografías y material hemerográfico de valor incalculable.

Sirvan las notas anteriores como el conjunto de ideas que ligaron también a Javier Sánchez Gámiz, bibliófilo cuya colección de obras taurinas se encuentra a buen recaudo en la Biblioteca Nacional de México, institución integrada a la Universidad Nacional Autónoma de México, que lo reconoció en su momento y bajo el principio universal de la cultura, haciendo suya esta valiosa pieza bibliográfica y hemerográfica que da lustre a sus propósitos.

\section{Bibliografía}

Barrios Ramos, Antonio. Mis libros de toros. México: Bibliófilos Taurinos de México, 1987.

Biblioteca "Carriquiri". http://www.grupogenova.net/ganaderia-y-biblioteca-carriquiri.

Biblioteca GARBOSA. http://www.bibliotoro.com/index.php.

Biblioteca Nacional (España). La fiesta nacional (ensayo de bibliografía taurina). Madrid: Artes Gráficas Clavileño, 1973.

Biblioteca Nacional de México. http://www.bnm.unam.mx/index.php/bibliotecanacional-de-mexico/colecciones/fondo-reservado/colecciones-especiales.

Bohórquez y Bohórquez, Enrique. El sentimiento del toreo. México: Imprenta Monterrey, 1961.

Catálogo de la Biblioteca de Carriquiri. Madrid: Biblioteca de Carriquiri, 1999.

Catálogo de la biblioteca taurina de d. Antonio Urquijo de Federico. Madrid: Artes Gráficas Arges, 1956.

${ }^{23}$ Salvador García Bolio, Bibliografía mexicana de la tauromaquia (Morelia: "Palacio del Arte", 1989) y El periodismo taurino en México (México: Bibliófilos Taurinos de México [s. a.]).

${ }^{24}$ Antonio Barrios Ramos, Mis libros de toros (México: Bibliófilos Taurinos de México, 1987).

${ }^{25}$ Luis Ruiz Quiroz, Libros, folletos y revistas taurinos (México: [s. e.], 1993). 
Catálogo de la biblioteca taurina de d. Eduardo Sotomayor Criado. Primer catálogo de la biblioteca taurina de d. Eduardo Sotomayor Criado. Córdoba, España: Talleres Gráficos R. Chaulé Sánchez, 1964.

Catálogo de la biblioteca taurina de Luis Carmena y Millán. Madrid: Oficina Tipográfica Ducazcal, 1903.

Catálogo de las publicaciones seriadas, anuarios, almanaques y revistas taurinas existentes en la Biblioteca Nacional de España. Redactado y ordenado por Fernando García Bravo. Madrid; Grupo M\&T, 2013.

Cossío, José María de. Los toros. Tratado técnico e histórico. Madrid: EspasaCalpe, 1974-1997, 12 vols.

Cuesta Baquero, Carlos (anagrama: Roque Solares Tacubac). Historia de la tauromaquia en el Distrito Federal desde 1885 hasta 1905. México: Tipografía José del Rivero, sucesor, y Andrés Botas, editor, [1905, 1920?], tomos 1 y 2.

Delgado, José. Tauromaquia o arte de torear a caballo y a pie: obra escrita por el célebre profesor Josef Delgado (vulgo) Hillo. Corregida y aumentada con una noticia histórica sobre el origen de las fiestas de toros en España. Adornada con treinta láminas que representan las principales suertes. Por un aficionado. Madrid: en la Imprenta de Vega y Compañía, calle de Capellanes. Ed. facsimilar. Madrid: Turner, 1978.

García Bolio, Salvador. El periodismo taurino en México. Historia. Fichas técnicas. Cabeceras. Con un prólogo de Alberto A. Bitar Letayf "A.A.B.", director de "El Redondel". Facsimilar. México: Bibliófilos Taurinos de México [s. a.].

García Bolio, Salvador. Asistencia médica. Plaza de toros de San Pablo 1845. Facsimilar. México: Bibliófilos Taurinos de México, 1985.

García Bolio, Salvador. Bibliografía mexicana de la tauromaquia. Por [...]. CartaPrólogo de D. Salvador Ferrer Irurzun, Presidente de la Unión de Bibliófilos Taurinos (España). Morelia: "Palacio del Arte", 1989.

La Lidia. Revista Gráfica Taurina, 1943.

Loret de Mola, Rafael. El triunfo del carácter. México: Bibliófilos Taurinos de México, 2015.

Maria y Campos, Armando de. Gaoneras (ensayos sobre estética taurina). México: "El Día Español", 1921.

Maria y Campos, Armando de. Los toros en México en el siglo XIX, 1810-1863. Reportazgo retrospectivo de exploración y aventura. México: Acción Moderna Mercantil, 1938.

Maria y Campos, Armando de. Breve historia del teatro en Chile... y de su vida taurómaca. México: Compañía de Ediciones Populares, S. A. (CEPSA), 1940. 
Maria y Campos, Armando de. Ponciano, el torero con bigotes. México: Ediciones Xóchitl, 1943.

Maria y Campos, Armando de. Andanzas y picardías de Eusebio Vela (autor y comediante mexicano del siglo XVIII). Con ilustraciones de la época. Facsimilar. México: CEPSA, 1944.

Maria y Campos, Armando de. Imagen del mexicano en los toros. México: "Al sonar el clarín", 1953.

Maria y Campos, Armando de. Vida dramática y muerte trágica de Luis Freg. Memorias y confesiones. México: Impresora Juan Pablos, 1958.

Maria y Campos, Armando de. Memorias de Vicente Segura. Niño millonario. Matador de toros. General de la Revolución. México: Compañía Editora y Distribuidora de Publicaciones, 1960, t. I.

Martínez, Eleuterio. Libros de toros. México: [s. e.], 1957-1962, 7 vols.

Ruiz Quiroz, Luis. Libros, folletos y revistas taurinos. México: [s. e.], 1993.

Sánchez de Neira, José. El toreo. Gran diccionario tauromáquico. Comprende todas las voces técnicas conocidas en el arte; origen, historia, influencia en las costumbres, defensa y utilidad de las corridas de toros; explicación detallada del modo de ejecutar cuantas suertes antiguas y modernas se conocen, lo cual constituye el más extenso arte de torear tanto a pie como a caballo, que se ha escrito hasta el día: Biografías, semblanzas, bocetos y reseñas de escritores, artistas, lidiadores y otras personas que con sus talentos, influencias o de cualquiera manera han contribuido al fomento de nuestra fiesta nacional; ganaderías, hierros, divisas, plazas, instrumentos del toreo, etc., etc. Por [...]. T. primero. Madrid: Imprenta y Librería de Miguel Guijarro, editor, 1879.

Vázquez [y Rodríguez], Leopoldo, Luis Gandullo et al. La Tauromaquia. Escrita por D. (...), D. (...) y D. Leopoldo López de Saa, bajo la dirección técnica del célebre diestro cordobés Rafael Guerra, Guerrita. Madrid: [s. e., s. a.].

Velázquez y Sánchez, José. Anales del toreo. Francisco Arjona Guillén, Cúchares (dir.). Sevilla: Delgado y Ca., editores; Juan Moyano, impresor y editor, 1868. $\triangleq \mathrm{bg}$ 